\title{
Cooling rate corrected paleointensities from the Xitle lava flow: Evaluation of within-site scatter for single spot-reading cooling units
}

\author{
Juan Morales ${ }^{1}$, Luis M. Alva-Valdivia ${ }^{1}$, Avto Goguitchaichvili ${ }^{1,2,3}$, and Jaime Urrutia-Fucugauchi ${ }^{1}$ \\ ${ }^{1}$ Laboratorio de Paleomagnetismo y Geofísica Nuclear, Instituto de Geofísica, UNAM, Ciudad Universitaria S/N, 04510, Mexico DF \\ ${ }^{2}$ Laboratorio Interinstitucional de Magnetismo Natural, Coeneo, Michoacan, México \\ ${ }^{3}$ At sabatic, Universidad Michoacana San Nicolas de Hidalgo, Departamento de Geologia y Mineralogia, México
}

(Received December 16, 2005; Revised June 17, 2006; Accepted July 24, 2006; Online published November 8, 2006)

\begin{abstract}
The historic Xitle lava, which covers a great part of southern Mexico City, is one of the most studied (magnetically) volcanic unit worldwide. Studies include detailed paleomagnetic and paleointensity investigations, which have documented an enigmatic within-flow variation of absolute paleointensity first recognized in the decade of 1960s. However, attempts to find possible explanations in terms of physical/magnetic parameters or geomagnetic effects have been unsatisfactory. As an effort to understand the over- and underestimating of geomagnetic paleointensity (PI) within the Xitle lava flow, we investigated the relation of the cooling rate upon the acquisition of thermoremanent magnetization (TRM). Contrary to archaeomagnetic investigations, most paleointensity experiments on volcanic rocks do not consider cooling rate effects in a systematic manner. Our results show that the scatter and overestimation of PI values obtained on the single Xitle lava flow are drastically reduced when using the cooling rate correction to raw selected data. The Thellier method combined with cooling rate experiments provide a higher precision compared to conventional Thellier and microwave techniques. The cooling rate effects upon acquisition of TRM in volcanic rocks seem to be as critical as in archaeomagnetic investigations.
\end{abstract}

Key words: Paleointensity, Thellier method, cooling rate effects, rock magnetism, Central Mexico.

\section{Introduction}

Volcanic rocks are considered as most reliable geomagnetic field recorders, capable of providing both directional and intensity information. Nonetheless, reliable absolute paleointensity values are generally much more difficult to obtain than reliable directional data, because volcanic rocks need to satisfy certain specific magnetic criteria (Thellier and Thellier, 1959; Kosterov and Prevot, 1998; Calvo et al., 2002; Coe et al., 2004; Chauvin et al., 2005) to be used for the paleointensity determination.

Conditions to be obeyed to ensure the significance of the paleointensity results are: a) Primary remanent magnetization must be a TRM (thermoremanent magnetization). b) Secondary components must be minor with respect to the primary component and must be removed at relatively low temperatures. c) The remanence must be carried mainly by single-domain magnetic grains to ensure the independence of the partial thermoremanent magnetizations (pTRM) (Thellier and Thellier, 1944), and d) no chemi$\mathrm{cal} /$ magnetic changes during laboratory heatings.

However, even when these basic conditions are fulfilled, paleointensity values are often under- and/or overestimated (Hill et al., 2000; Calvo et al., 2002; Urrutia-Fucugauchi et al., 2004). An interesting example in this context is the single Xitle lava flow in Central Mexico. High quality Thellier paleointensity experiments (Böhnel et al., 1997, 2003 and

Copyright (c) The Society of Geomagnetism and Earth, Planetary and Space Sciences (SGEPSS); The Seismological Society of Japan; The Volcanological Society of Japan; The Geodetic Society of Japan; The Japanese Society for Planetary Sciences; TERRAPUB
Morales et al., 2001) yield values ranging from 48.2 to 86.8 $\mu \mathrm{T}$. Microwave analysis performed on almost same samples (Böhnel et al., 2003) gave values ranging from 46 to $78.4 \mu \mathrm{T}$. Thus, both conventional and microwave Thellier methods show similarly large within-flow variation, which is troubling if it is considered that all samples are expected to have acquired their remanence synchronously.

In this study, we report new experimental data to evaluate the effect of cooling rate on the intensity of TRM and the possible implications on Thellier paleointensity determination. Systematic scatter and overestimating of paleointensity values obtained in the single lava flow from Xitle volcano is drastically reduced when using cooling rate correction to raw selected data.

\section{Samples}

The monogenetic Xitle volcano belongs to the Chichinautzin monogenetic volcanic field (Delgado et al., 1998). The young lava flows are well exposed and preserved, showing flow textures and morphology with no apparent alteration. They cover the archaeological sites of Cuicuilco and Copilco and have been extensively studied, including the first paleomagnetic and radiocarbon dating studies in the country in the 1940s and 1950s. Near to the university campus of the National University of Mexico (UNAM), we selected a $4.3 \mathrm{~m}$ thick massive and fresh outcrop (Fig. 1). Twenty-two standard paleomagnetic cores were obtained along a vertical profile using a portable gasoline drill.

Cores were cut into 2 to 4 specimens; 1 to 2 were used for PI determination while the rest were dedicated to rock mag- 

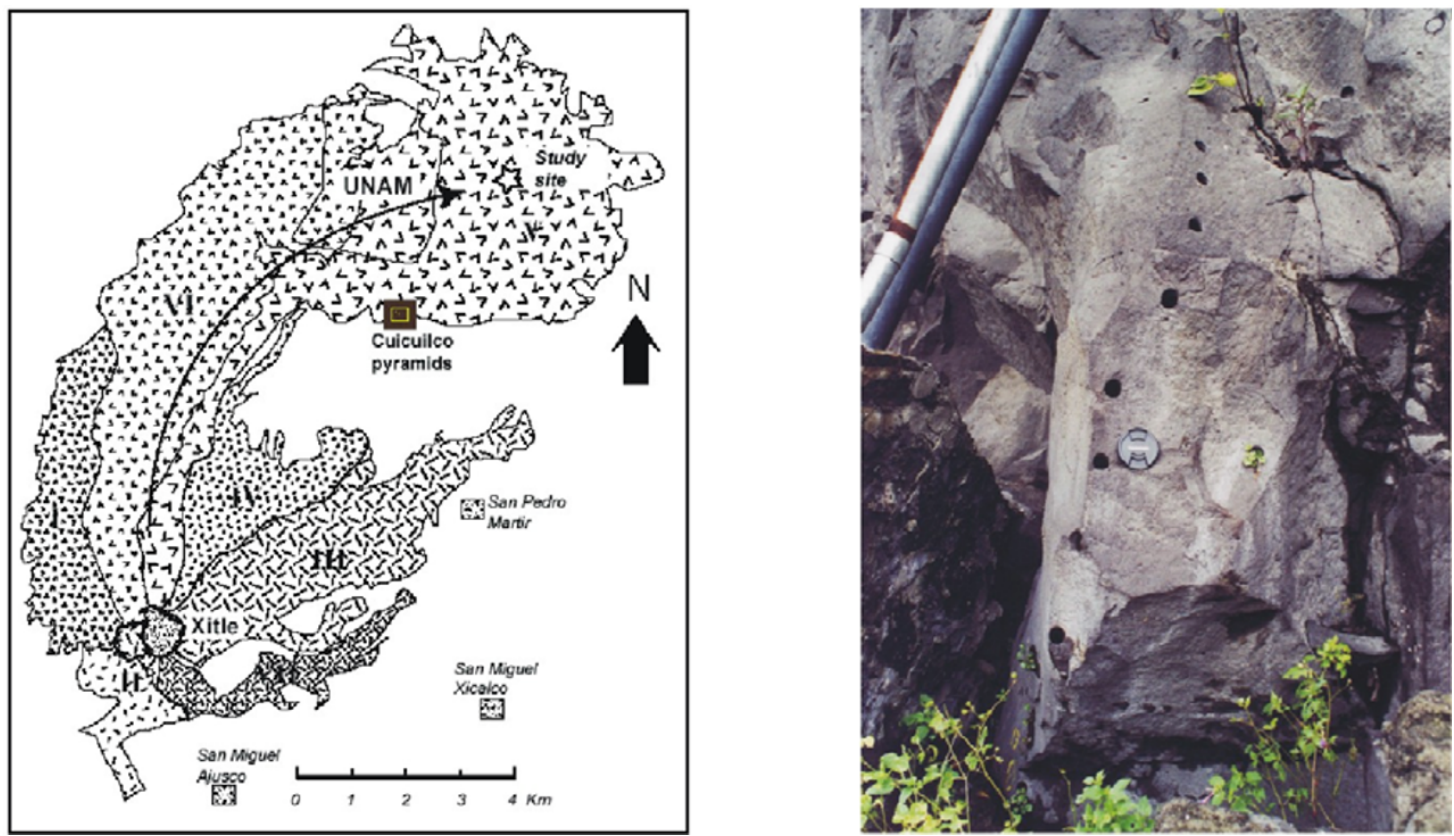

Fig. 1. Location of sampled site (adopted from Delgado et al., 1998).
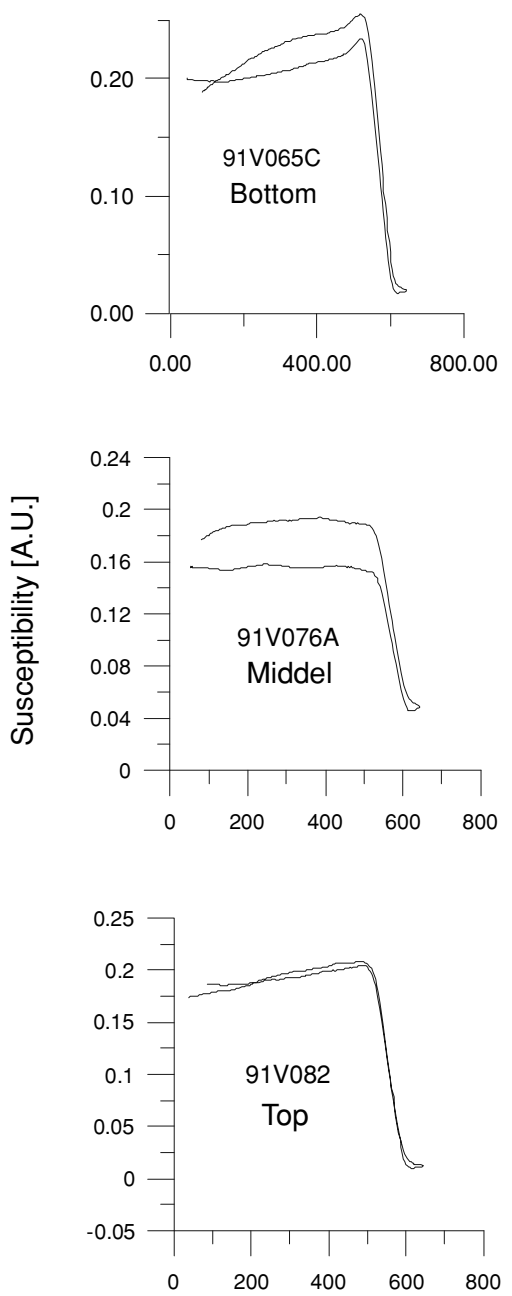

Temperature $\left[{ }^{\circ} \mathrm{C}\right]$

Fig. 2. Representative continuous susceptibility versus temperature curves. netic properties. Detailed descriptions of magnetic properties of Xitle samples are given in Morales et al. (2001) and (2003) and can be summarized here as follows: Samples show very stable, uni-vectorial remanent magnetization revealed by thermal and alternating field demagnetizations. The main magnetic carriers are low-Ti titanomagnetites (resulting from deuteric oxi-exsolution) as evidenced by reasonably reversible susceptibility versus temperature curves (Fig. 2) and microscopy observation.

Hysteresis measurements at room temperature were performed on all samples using the AGFM 'Micromag' apparatus in fields up to 1.0 Tesla. These measurements have allowed the determination of saturation magnetisation, $M_{s}$, saturation of remanence, $M_{r s}$ and coercivity, $H_{c}$. Samples were given an IRM, their magnetisation measured, and then the backfield IRM was applied, giving an indication of the coercivity of remanence, $H_{c r}$. Combining hysteresis, backfield IRM, coercivity and saturation data allows estimate the bulk magnetic grain size. Some typical hysteresis plots are reported in Fig. 3.

The ratios of hysteresis parameters indicate that all samples fall in the pseudo-single domain grain size region, probably indicating a mixture of multidomain and a significant amount of single domain grains. This last assumption is reinforced by the presence of a well defined Hopkinson peak in Fig. 2 (Bottom), indicating SD magntetite as the main magnetic carrier (see also Dunlop and Özdemir, 1997).

Judging from 'Middle' IRM curve at Fig. 3, it may be speculated the presence of a second magnetic component, which probably correspond to some titanohematites since no saturation is reached. We also note that $M_{r s}$ and $M_{s}$ histeresis parameters (Fig. 3) yield roughly half of the magnetization with respect to the Bottom and Top zones. This may indicate to some variation in magnetic concentration and/or magnetic mineralogy. 

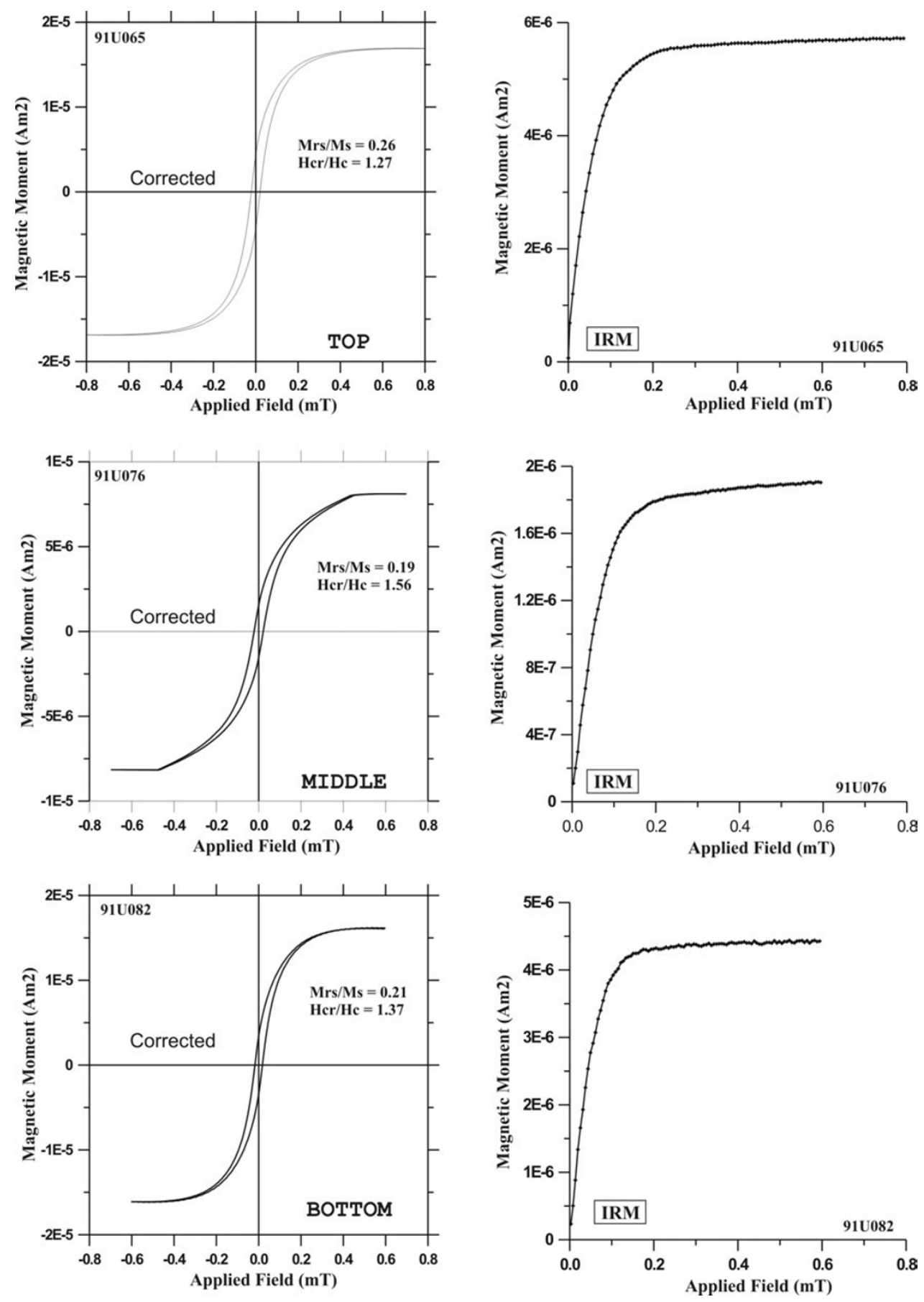

Fig. 3. Representative hysteresis plots obtained with an 'AGFM-Micromag' apparatus.

\section{Laboratory Procedures}

Paleointensity (PI) experiments were performed following the method developed by Thellier and Thellier (1959) as modified by Coe (1967). Twelve increasing temperature steps were distributed through the whole experiments. Measurements of remanences were carried out using a JR6 spinner magnetometer.

Cooling rate dependence on TRMs was investigated following a modified procedure to that described by Chauvin et al. (2000). TRM gained during last step of Thellier experiment (in our case $575^{\circ} \mathrm{C}$ ) was subsequently designated as $\mathrm{TRM}_{1}$. At the same temperature, a new TRM $\left(\mathrm{TRM}_{2}\right)$ was given to all samples but now using a long cooling time
( $\sim 12$ hrs.). Finally, a third TRM $\left(\mathrm{TRM}_{3}\right)$ was created using the same cooling time (of about $45 \mathrm{~min}$ ) as that used to create $\mathrm{TRM}_{1}$. The effect of cooling rate upon TRM intensity was estimated by calculating the percent variation $\left(R_{12}\right)$ between the intensity acquired during a short and a long cooling time $\left(\mathrm{TRM}_{1}\right.$ and $\left.\mathrm{TRM}_{2}\right)$, whereas variation in the TRM acquisition capacity was estimated as percent variation $\left(\mathrm{R}_{13}\right)$ between the intensity acquired during the same cooling time $\left(\mathrm{TRM}_{1}\right.$ and $\left.\mathrm{TRM}_{3}\right)$.

\section{Results and Discussion}

Conventional Thellier experiments performed on our collection of Xitle samples give moderate high quality determi- 
Table 1. Summary of paleointensity experiments: $d$, distance above flow base; $\mathrm{T}_{\min }-\mathrm{T}_{\max }$, the temperature range used for PI estimation; $n$, number of NRM-TRM points used for determination; $\mathrm{PI}_{\mathrm{UC}}$, uncorrected paleointensity; s.d., standard deviation of $\mathrm{PI}_{\mathrm{UC}}$; $\mathrm{PI}_{\mathrm{CRC}}$, cooling rate corrected paleointensity; $f, g$ and $q$ : fraction of extrapolated NRM used for intensity determination, gap and quality factor (Coe et al., 1978), respectively; $\mathrm{R}_{13}$, estimated variation in TRM acquisition capacity; The laboratory field was set $28.5 \mu \mathrm{T}$ during the experiment.

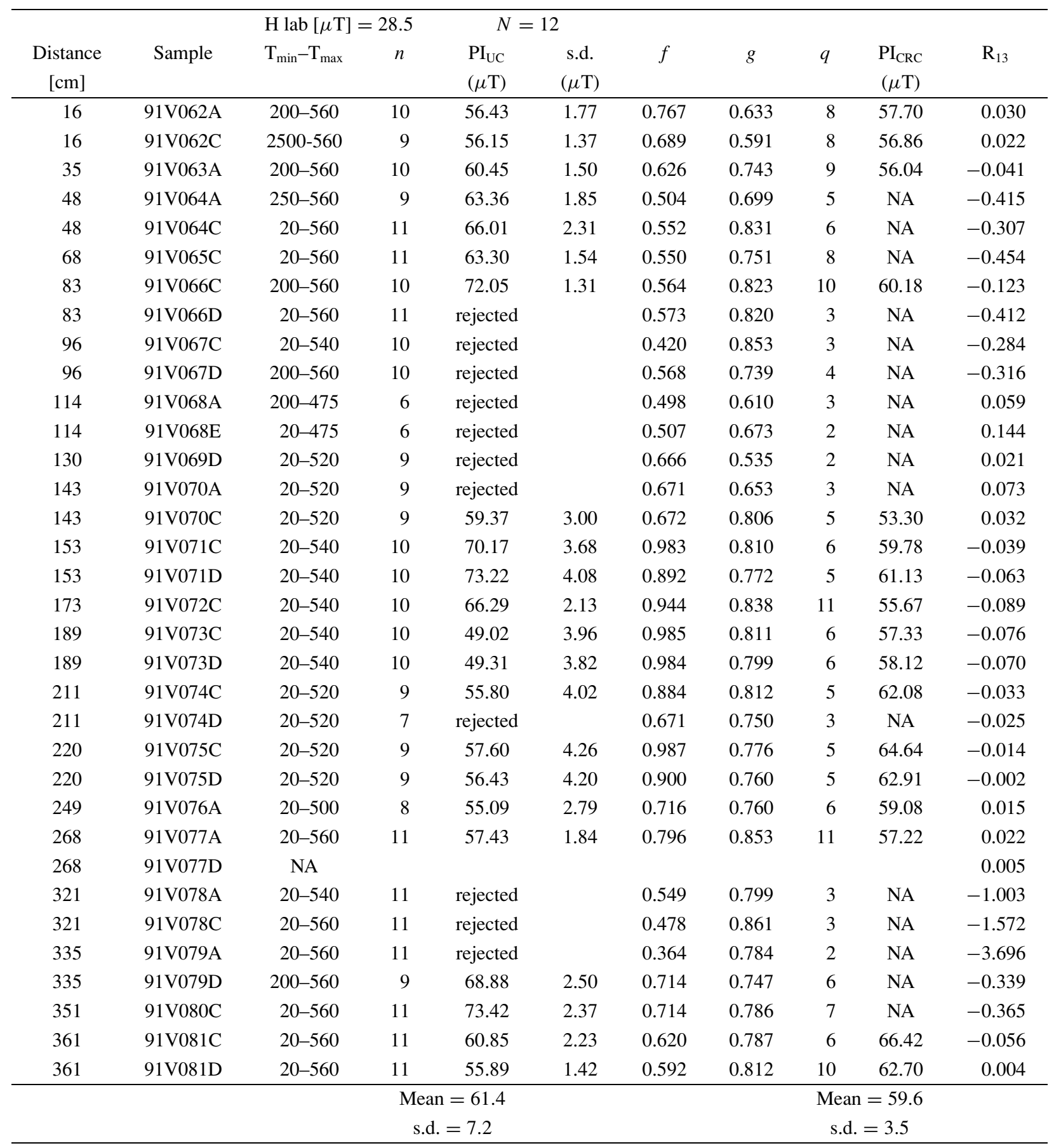

nations. Paleointensity data are reported on the Arai-Nagata (Nagata et al., 1963) plots on Fig. 4 and summarised in Table 1. For accepted samples the NRM fractions used for paleointensity determination range from 0.36 to 0.98 and the quality factors varies between 5 and 10, being normally greater than 5 (Table 1 ). Similarly to previous studies (Böhnel et al., 1997, 2003; Morales et al., 2001, 2003), where both conventional and microwave methods are involved, our selected paleointensity data (positive pTRM checks, NRM fraction higher than $1 / 3$ and the quality factor higher than 5), yield unacceptable scatter for a single lava flow ranging from 49.0 to $73.42 \mu \mathrm{T}$ and giving a mean of $61.4 \pm 7.2 \mu \mathrm{T}$.

Paleomagnetic data from a single cooling unit provides a spot reading of the paleofield, and the paleointensity scatter observed within single Xitle lava has no geomagnetic origin. Rock magnetic and mineralogical factors may also be discarded since no relationship was found between magnetic parameters and absolute intensity. Cooling rate effect on the intensity of thermoremanent magnetization has 

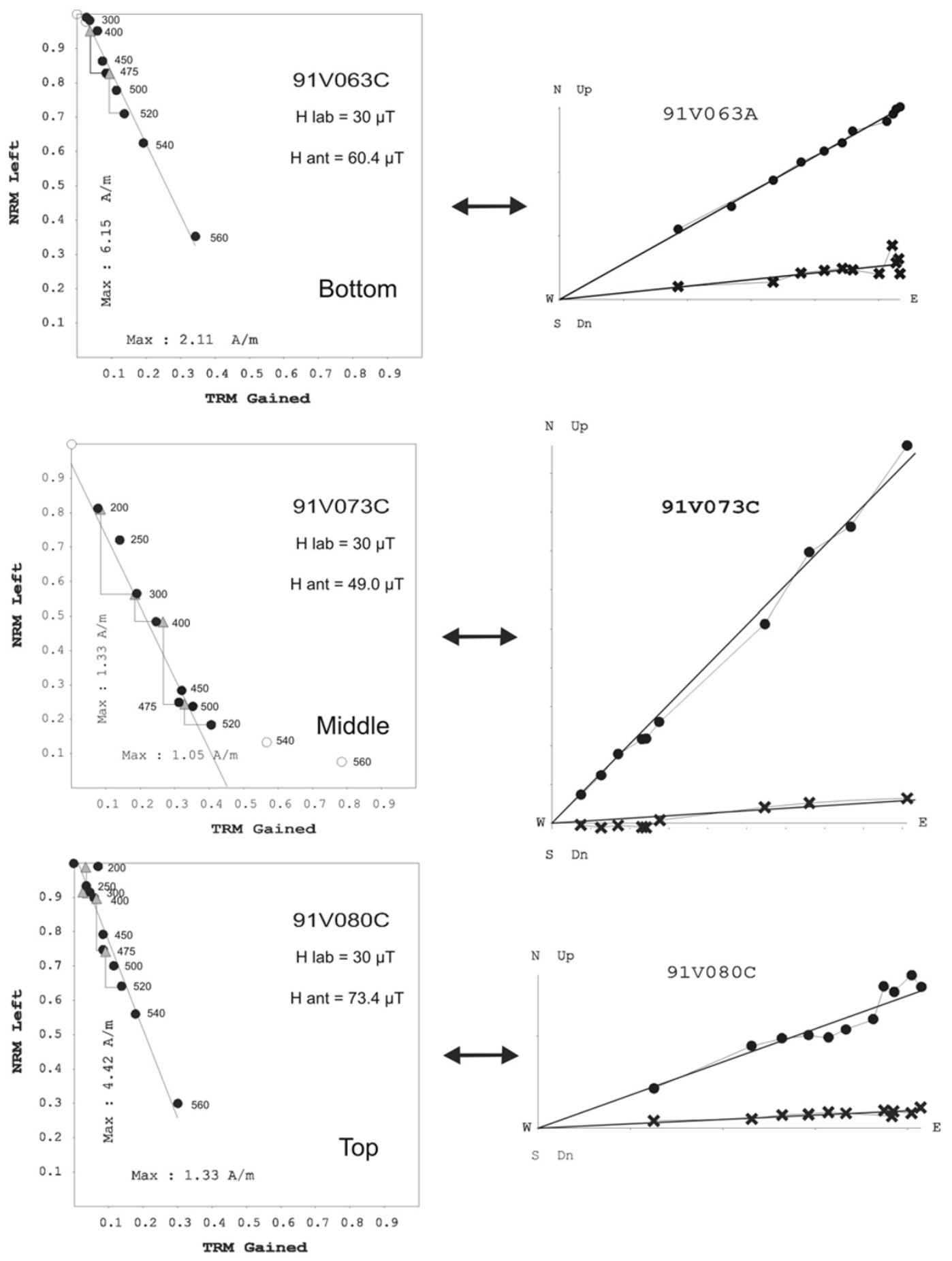

Fig. 4. Typical Arai Plot for samples from bottom, middle and top of flow.

been previously documented for archaeomagnetic material, where cooling in laboratory conditions are generally much faster compared to natural cooling. This phenomenon usually results in overestimating of the paleofield by some 5$10 \%$. Although this effect may have important implications for paleointensity determinations (Le Goff, 2004; Chauvin et al., 2005), cooling rate correction on volcanic rocks is not a common practice (Perrin, 1998) and only few studies take this effect into account (e.g., Pick and Tauxe, 1993; Carlut and Kent, 2002; Bowles et al., 2005). These firstrate rock magnetic investigations motivated us to consider the cooling rate effect for Xitle samples. Cooling rate cor- rection of raw PI values was based on the premise that $\mathrm{R}_{13}$ should be lower than $15 \%$. This attests that no major changes occur in TRM acquisition capacity (see Chauvin et $a l ., 2000)$. Thus, we rejected all data when $\mathrm{R}_{13}$ parameter exceeds $15 \%$ (Fig. 5(a), left hand axis). Additionally, we rejected data showing commonly unacceptable Coe's quality factors (basically $q$ lower than 5). We note also that even samples yielding $q$ factors higher than 5 may have $\mathrm{R}_{13}$ values exceeding 15\% (Fig. 5(a), right hand axis). The cooling rate corrected data (refer here as TCR) show no significant within-flow variation since the higher/lower values are decreased/increased, as illustratively indicated by the arrows 
Height above flow base $[\mathrm{cm}]$

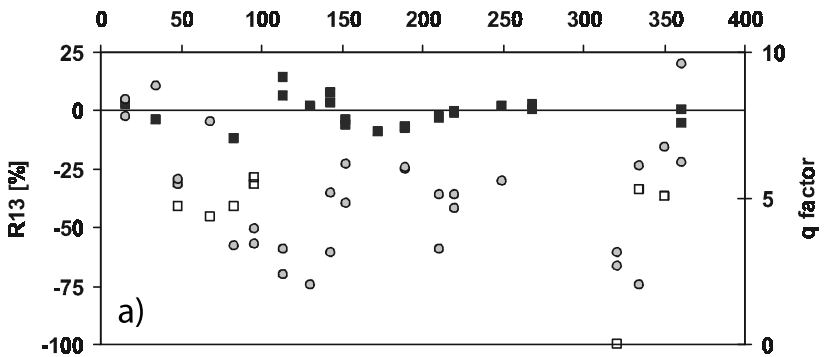

- $\mathrm{R} 13<15 \%$ व $\mathrm{R} 13>15 \% \circ \mathrm{q}$

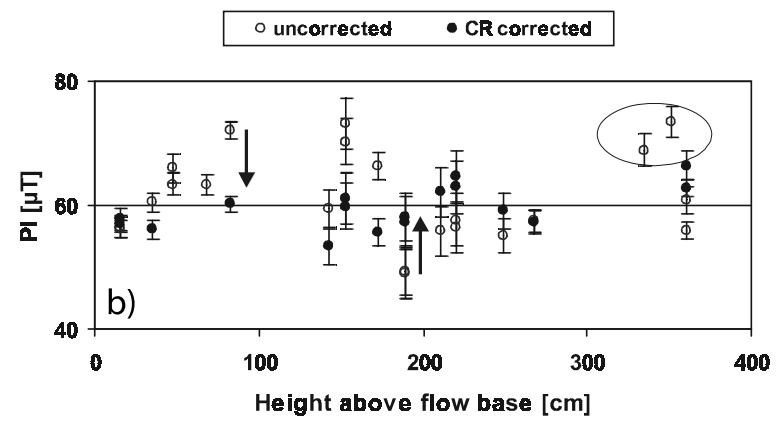

Fig. 5. a) $\mathrm{R}_{13}$ and $q$ quality factor , b) Raw and CR corrected PI data plot; variation along the profile, respectively. Arrows indicate the tendency of displacement that uncorrected PI data experienced after CR correction. Ellipses enclose uncorrected data point values excluded according to CR criteria.

in Fig. 5(b) (see also Table 1 and Fig. 6(a)). The absolute paleointensities obtained after the CR correction range from 53.30 to $64.64 \mu \mathrm{T}$. Conventional Thellier method give much larger interval from 48.2 to $86.8 \mu \mathrm{T}$ while microwave technique show the variation from 46.0 to $78.4 \mu \mathrm{T}$. The mean value obtained here is $59.6 \pm 3.5 \mu \mathrm{T}$ against $67.5 \pm 9.8$ $\mu \mathrm{T}$ and $58.3 \pm 9.5$ using conventional and microwave Thellier methods respectively (see Fig. 6(a) and (b)).

Single cooling units provide spot readings of the geomagnetic field, with good reliability in most cases. Scatter in individual PI determinations then reflects effects related to magnetic mineralogy (oxidation/reduction of oxide minerals, domain states and grain sizes, etc), local magnetic anomaly effects, or methodological problems related to e.g., alterations on the TRM acquisition capacity. High scatter then implies one or more problems involved in the PI experiments; whereas reduced scatter reflects higher precision (but not necessarily increased reliability). The mean value and standard deviation of the selected paleointensity data previously derived from double-heating Thellier experiments were (samples used/samples analyzed, $\mathrm{Ns} / \mathrm{No}=$ $25 / 65) 67.5 \pm 9.8 \mu \mathrm{T}$ and from microwave experiments were $(N s / N o=17 / 19) 58.3 \pm 9.5 \mu \mathrm{T}$ (Böhnel et al., 2003). Individual determinations range from 48.2 to 86.8 and 46.0 to $78.4 \mu \mathrm{T}$ for the Thellier and microwave experiments. The mean PI and standard deviation obtained before application of the cooling rate correction are $61.4 \pm 7.2 \mu \mathrm{T}$, with a range from 49.0 to $73.42 \mu \mathrm{T}$. The TCR PI data provide a mean PI value with reduced scatter and improved
Xitle TCL

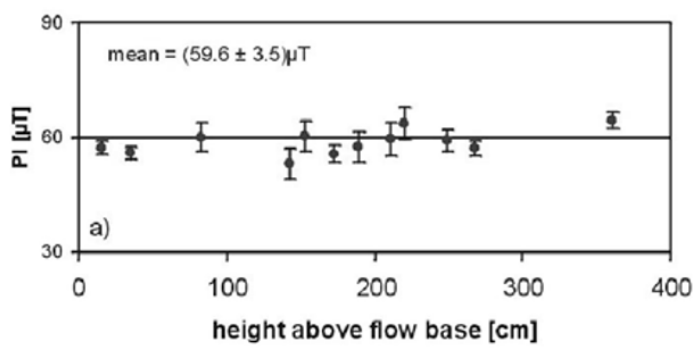

Xitle $\mu \mathrm{W}$

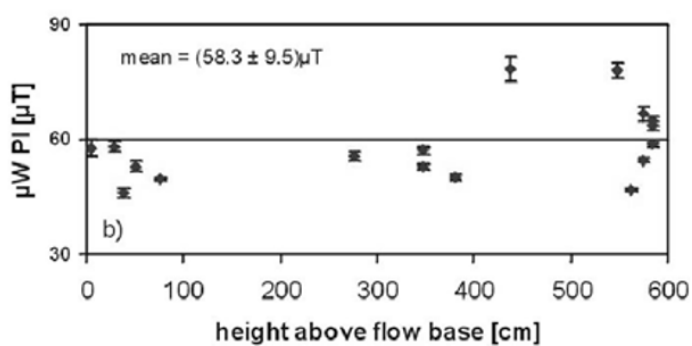

Fig. 6. (a) CR corrected Thellier-Coe (This Study) and (b) microwave (Böhnel et al., 2003) PI data plot.

precision in the determination of the paleointensity for the Xitle lava flow.

Investigation of cooling rate dependence on TRMs, combined with the use of strict acceptance criteria, seems to be a powerful tool to explain the systematic intra-flow scatter of PI data. The effect of cooling rate upon acquisition of TRM in volcanic rocks seems to be as critical as in archaeomagnetic investigations.

Acknowledgments. The constructive comments of Mireille Perrin and Carlos A. Vasquez on an early version of the manuscript are highly appreciated. We thank Jose Antonio Gonzalez for assistance with the measurements. AG acknowledges the financial support of UNAM-PAPIIT project IN100403, CONACYT no. 42661 and Direción General de Asuntos del Personal Académico (UNAM) for the sabbatical fellowship.

\section{References}

Bowles, J., J. Gee, D. Kent, E. Bergmanis, and J. Sinton, Cooling rate effects on paleointensity estimates in submarine basaltic glass and implications for dating young flows, Geochem. Geophys. Geosyst., 6, Q07002, 2005.

Böhnel, H., J. Morales, C. Caballero, L. Alva, G. McIntosh, S. Gonzales, and G. J. Sherwood, Variation of Rock Magnetic Parameters and Paleointensities over a Single Holocene Lava Flow, J. Geomag. Geoelectr., 49, 523-542, 1997.

Böhnel, H., A. J. Biggin, D. Walton, J. Shaw, and J. A. Share, Microwave paleointensities from a recent Mexican lava flow, baked sediments and reheated pottery, Earth Planetary Sci. Lett., 214, 221-236, 2003.

Calvo, M., M. Prévot, M. Perrin, and J. Riisager, Investigating the reasons for the failure of paleointensity experiments: A study on historical lava flows from Mt. Etna (Italy), Geophys. J. Int., 149, 44-63, 2002.

Carlut, J. and D. V. Kent, Grain-size-dependent paleointensity results from very recent mid-oceanic ridge basalts, J. Geophys. Res., 107(B3), 10.1029/2001JB00439, 2002.

Coe, R., Paleointensity of the Earth's magnetic field determined from Tertiary and Quaternary rocks, J. Geophys. Res., 72(12), 3247-3262, 1967.

Coe, R., S. Grommé, and E. A. Mankinen, Geomagnetic paleointensity from radiocarbon-dated flows on Hawaii and the question of the Pacific nondipole low, J. Geophys. Res., 83, 1740-1756, 1978. 
Coe, R., L. Hongre, and G. Glatzmaier, An examination of simulated geomagnetic reversals from a plaeomagnetic perspective, Phil. Trnas. R. Soc. Lond. A, 358, 1141-11710, 2004.

Chauvin, A., Y. Garcia., Ph. Lanos, and F. Laubenheimer, Paleointensity of the geomagnetic field recovered on archaeomagnetic sites from France, Phys. Earth Planet. Int., 120, 111-136, 2000.

Chauvin, A., P. Roperch, and S. Levi, Reliability of geomagnetic paleointensity data: the effects of the NRM fraction and concave-up behavior on paleointensity determinations by the Thellier method, Phys. Earth Planet Int., 150, 265-286, 2005.

Delgado, H., R. Molinero, P. Cervantes, J. Nieto-Obregón, R. LozanoSanta Cruz, H. L. Macias-Gonzáles, C. Mendoza-Rosales, and G. SilvaRomo, Geology of the Xitle volcano in southern Mexico-City-A 2000 years-old monogenetic volcano in an urban area, Rev. Mex. Ciencias Geol., 15(2), 115-131, 1998.

Dunlop, D. and Ö. Özdemir, Rock Magnetism, Fundamentals and Frontiers, Cambrige University Press, 573 pp., 1997.

Hill, M. and J. Shaw, Magnetic field intensity study of the 1960 Kilauea lava flow, Hawaii, using the microwave paleointensity technique, Geophys. J. Int., 142, 487-504, 2000.

Kosterov, A. and M. Prevot, Possible mechanism causing failure of Thellier paleointensity experiments in some basalts, Geophys. J. Inter., 134, 554-572, 1998.

Le Goff, M. and Y. Gallet, A new three-axis vibrating sample magnetometer for continuous high-temperature magnetization measurements: applications to paleo- and archeo-intensity determinations, Earth Planetary Sci. Lett., 229, 31-43, 2004.

Morales, J., A. Goguitchaichvili, and J. Urrutia-Fucugauchi, A rock- magnetic and paleointensity study of some Mexican volcanic lava flows during the Latest Pleistocene to Holocene, Earth Planets Space, 53, 893-902, 2001.

Morales, J., A. Goguitchaichvili, and J. Urrutia-Fucugauchi, An experimental evaluation of Shaw's paleointensity method and its modifications using Late Quaternary basalts, Phys. Earth Planet Int., 138, 1-10, 2003.

Nagata, T., Y. Arai, and K. Momose, Secular variation of the geomagnetic total force during the last 5000 years, J. Geophys. Res., 68, 5277-5281, 1963.

Perrin, M., Paleointensity determination, magnetic domain structure, and selection criteria, J. Geophys. Res., 103(B12), 30591-30600, 1998.

Pick, T. and L. Tauxe, Holocene Paleointensities: Thellier Experiments on Submarine Basaltic Glass From the East Pacific Rise, J. Geophys. Res., 98(B10), 17949-17964, 1993.

Thellier, E. and O. Thellier, Recherches géomagnetiques sur les coulees volcaniques d'Auvergne, Ann. Geophys., 1, 37-52, 1944.

Thellier, E. and O. Thellier, Sur l'intensité du champ magnétique terrestre dans le passé historique et géologique, Ann. Géophysique., 15, 285-376, 1959.

Urrutia-Fucugauchi, J., L. M. Alva-Valdivia, A. Goguitchaichvili, M. L. Rivas, and J. Morales, Paleomagnetic, rock-magnetic and microscopy studies of historic lava flows from the Paricutin volcano, Mexico: implications for the deflection of paleomagnetic directions, Geophys. J. Int., 156, 431-442, 2004.

J. Morales (e-mail: jmorales@geofisica.unam.mx), L. M. AlvaValdivia, A. Goguitchaichvili, and J. Urrutia-Fucugauchi 